\title{
Pharmacokinetics of xanthohumol in rats of both sexes after oral and intravenous administration of pure xanthohumol and prenylflavonoid extract
}

\author{
Beata Nowak ${ }^{1, A-D, F}$, Błażej Poźniak ${ }^{2,-}$, , Jarosław Popłoński, ${ }^{3, A, C-F}$, Łukasz Bobak k, ,E,F, Agnieszka Matuszewska ${ }^{1, B, E, F}$, \\ Joanna Kwiatkowska ${ }^{1, B, F}$, Wojciech Dziewiszek ${ }^{1, B, E, F}$, Ewa Huszcza ${ }^{3, A, C, E, F}$, Adam Szeląg ${ }^{1, A, E, F}$ \\ ${ }^{1}$ Department of Pharmacology, Faculty of Medicine, Wroclaw Medical University, Poland \\ 2 Department of Pharmacology and Toxicology, Faculty of Veterinary Medicine, Wroclaw University of Environmental and Life Sciences, Poland \\ ${ }^{3}$ Department of Chemistry, Faculty of Biotechnology and Food Science, Wroclaw University of Environmental and Life Sciences, Poland \\ A - research concept and design; $\mathrm{B}$ - collection and/or assembly of data; $\mathrm{C}$ - data analysis and interpretation; \\ $D$ - writing the article; $E$ - critical revision of the article; $F$ - final approval of the article
}

Address for correspondence

Beata Nowak

E-mail: beata.nowak@umed.wroc.pl

Funding sources

National Science Centre, Poland,

Grant No. 2016/21/B/NZ7/02759.

Conflict of interest

None declared

Received on April 28, 2020

Reviewed on May 20, 2020

Accepted on August 11, 2020

Published online on September 30, 2020

Cite as

Nowak B, Poźniak B, Popłoński J. Pharmacokinetics of xanthohumol in rats of both sexes after oral and intravenous administration of pure xanthohumol and prenylflavonoid extract. Adv Clin Exp Med. 2020;29(9):1101-1109. doi:10.17219/acem/126293

DOI

10.17219/acem/126293

Copyright

Copyright by Author(s)

This is an article distributed under the terms of the

Creative Commons Attribution 3.0 Unported (CC BY 3.0)

(https://creativecommons.org/licenses/by/3.0/)

\begin{abstract}
Background. Female inflorescences of hops (Humulus lupulus L.) are wildly used in the brewing industry. Hops have been also used for ages in folk medicine. Xanthohumol (XN) is a most abundant prenylated flavonoid present in hops.

Objectives. To determine pharmacokinetic parameters and bioavailability of pure XN and XN given in prenylflavonoid extract obtained from spent hops (HOP).

Material and methods. Fifty-six Wistar rats (28 females and 28 males) were administered with XN or HOP. Xanthohumol was administered either intravenously (iv.) (10 mg/kg) or orally (per os (p.0.)) (40, 100 and $200 \mathrm{mg} / \mathrm{kg}$ ). Extract obtained from spent hops was administered p.o. and its doses were based on XN content (doses were equivalent to XN dose of 40, 100 and $200 \mathrm{mg} / \mathrm{kg}$, respectively). After administration of XN or HOP serum, XN concentration was measured at different time points $(0,0.25,0.5,1,2,4,6,12,24$, 48, 72, and 96 h). Non-compartmental analysis was used to assess the pharmacokinetics (PK) of XN in rats.

Results. The XN PK in rats after intravenous administration is characterized by extensive distribution followed by delayed elimination from the body. Enterohepatic recirculation is likely to play a role in XN PK. Some fraction of the orally administered XN reaches central compartment rapidly; however, the overall absorption is very limited and probably saturable. The formulation-dependent factors also play an important role in the bioavailability of the drug. Although the CMAX concentration was higher in female rats receiving XN orally comparing to males, the other pharmacokinetic parameters were unaffected by the rats' sex.
\end{abstract}

Conclusions. The same doses of XN may be administered to male and female subjects, as its pharmacokinetics is not affected by sex.

Key words: bioavailability, pharmacokinetics, prenylflavonoid, rat, xanthohumol 


\section{Introduction}

Female inflorescences of hops (Humulus lupulus L.) are wildly used in the brewing industry to preserve beer and to give beer aroma and flavor. Apart from being used in the brewing industry, hops have been used for ages in folk medicine. In traditional medicine, hops are used mainly to treat sleep disturbances. However, they are also used as stomachic, antibacterial and antifungal remedy. ${ }^{1}$ They have also been known to be estrogenic, ${ }^{2}$ and herbal remedies containing hops are used to alleviate menopausal symptoms. ${ }^{3}$ Prenylated flavonoids belong to substances present in hops that contribute to their bioactivity, and xanthohumol (XN, Fig. 1) is the most abundant prenylated flavonoid present in hops.<smiles>COc1cc(O)c(CC=C(C)C)c(O)c1C(=O)/C=C/c1ccc(O)cc1</smiles>

Fig. 1. Chemical structure of xanthohumol (XN)

Very few studies have been published on pharmacokinetics of XN and hop prenylflavonoids. On the one hand, reported studies investigated low doses of XN (1-17 mg/kg orally, $1.86 \mathrm{mg} / \mathrm{kg}$ intravenously (iv.)) and only male rats were used in these studies. ${ }^{4}$ On the other hand, toxicological studies revealed that very high doses of XN are safe. The dose of $500 \mathrm{mg} / \mathrm{kg}$ induced no toxic effects and the dose of $1000 \mathrm{mg} / \mathrm{kg}$ was associated only with mild hepatotoxicity. ${ }^{5}$ Taking these facts into account, we decided to investigate the pharmacokinetics of higher doses of $\mathrm{XN}$ and to investigate rats of both sexes. Additionally, we decided to compare pharmacokinetics of 2 formulations of $\mathrm{XN}$ (pure $\mathrm{XN}$ and $\mathrm{HOP}$ ) to evaluate whether compounds in extracts, mainly other prenylflavonoids, present in the extract affect the bioavailability of $\mathrm{XN}$ and its pharmacokinetics.

The aim of the present study was to compare the pharmacokinetic (PK) parameters of XN and prenylfavonoid extract in Wistar rats of both sexes, and to determine the influence of sex on the pharmacokinetics of XN. A single dose pharmacokinetic study was conducted at 3 oral (per os (p.o.)) dose levels and 1 iv. dose level in order to determine the bioavailability of XN and dependence of pharmacokinetic parameters on dose level, formulation (pure $\mathrm{XN}$ or HOP) and sex.

\section{Material and methods}

\section{Plant materials and samples preparation of prenylflavonoid extract and xanthohumol}

Xanthohumol and HOP used in animal studies were obtained from brewing industry waste - spent hops (Fig. 2). Spent hops were obtained from production of hop extracts (New Chemical Syntheses Institute, Puławy, Poland) by supercritical carbon dioxide extraction of hops Humulus lupulus cv. Magnum collected in 2015 in Lublin region (SE, Poland).

Prenylflavonoid extract was obtained as a result of semi-industrial and laboratory process. The first stage of production started at Wrocław Technology Park (Poland), where $92 \mathrm{~kg}$ of spent hops were added to $0.8 \mathrm{~m}^{3}$ of acetone (POCH, Gliwice, Poland) in the batch reactor $\left(2 \mathrm{~m}^{3}\right)$ for $2 \mathrm{~h}$ with continuous stirring $(120 \mathrm{rpm})$. The pulp formed was stirred for another $2 \mathrm{~h}$ at $30^{\circ} \mathrm{C}$, left for sedimentation, and acetone fraction was pumped through a cotton bag filter $(0.1 \mathrm{~mm}$ mesh) to vacuumevaporatory module and the extract was concentrated

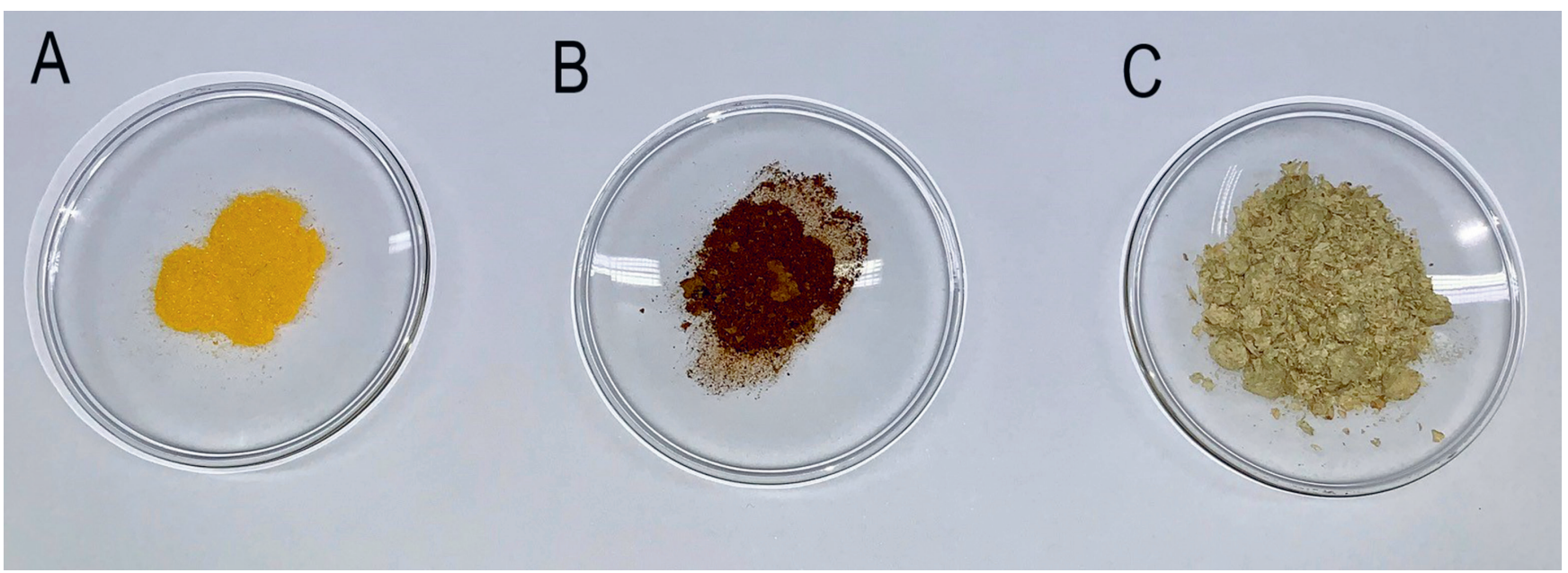

Fig. 2. Pure xanthohumol (A) prenylflavonoid extract (B) and spent hops (C) 
under vacuum at $40^{\circ} \mathrm{C}$ to a volume of about $40 \mathrm{~L}$, stored in a high-density polyethylene (HDPE) industrial barrel closed under nitrogen atmosphere at room temperature and used directly in further laboratory purification steps. Half a liter of the extract was concentrated with a rotary-evaporator to volume, at which the beginning of precipitation was observed, typically to about $80 \mathrm{~mL}$; then $100 \mathrm{~mL}$ of ice cold $1 \mathrm{M} \mathrm{NaOH}$ was added, followed by $400 \mathrm{~mL}$ of cold distilled water. The slurry obtained was centrifuged for $4 \mathrm{~min}$ at $3000 \times \mathrm{g}$ and the resulting supernatant was collected and acidified with ice-cold $1 \mathrm{M} \mathrm{HCl}$. A new precipitate was formed, collected, washed with cold distilled water, air dried and stored at $-20^{\circ} \mathrm{C}$. The precipitates (prenylflavonoid extract - HOP) consisting mainly XN (121 mg/g dry weight), isoxanthohumol (IXN), $41 \mathrm{mg} / \mathrm{g}$ dry weight) and polyphenol fraction were pooled, air dried, grinded and further used directly in animal studies or in the purification of $\mathrm{XN}$.

Portions, 5-6 g, of precipitate were dissolved in $30 \mathrm{~mL}$ of $\mathrm{MeOH}(\mathrm{POCH})$ and purified on column chromatography with Sephadex LH 20 (GE Healthcare, Chicago, USA) and methanol as a mobile phase. Fractions were analyzed by TLC (Merck Silica Gel 60, F254, 0.2 mm, eluent: chlorophorm: methanol $(9: 1 \mathrm{v} / \mathrm{v}))$ and fractions containing only $\mathrm{XN}$ were collected, evaporated and used after additional air drying in animal studies ( $>98 \%$ purity by HPLC/NMR). 6-prenylnaringenin (6PN), xanthohumol B (XN B) and xanthohumol D (XN D) standards were obtained as byproducts during the purification of $\mathrm{XN}$ (results not shown). Xanthohumol C (XN C) was obtained by chemical oxidative cyclisation, ${ }^{6}$ isoxanthohumol (IXN) by chemical isomerization of $\mathrm{XN}^{7}$ and $8 \mathrm{PN}$ was obtained by chemical demethylation of XN. ${ }^{8}$

The XN content in XN batches and HOP was evaluated by HPLC on a Dionex Ultimate 3000 instrument (Thermo Fisher Scientific, Waltham, USA) with a diode array detector (detection at $360 \mathrm{~nm}$ wavelength) using the analytical HPLC column Agilent ZORBAX Eclipse XDB (Aligent, Santa Clara, USA) $5 \mu \mathrm{m}(4.6 \times 250 \mathrm{~mm})$. Elution was carried out with a gradient of $40 \%$ to $100 \%$ of solvent B ( $1 \%$ formic acid in $\mathrm{MeCN}$ ) in solvent $\mathrm{A}$ (aqueous $1 \%$ formic acid) in $15 \mathrm{~min}$ at the flow rate of $0.8 \mathrm{~mL} / \mathrm{min}$ after the initial 2 min at $40 \%$ solvent B, then from $100 \%$ to $40 \%$ of solvent $B$ over the course of $7 \mathrm{~min}$ and held for $2 \mathrm{~min}$ in $40 \%$ of solvent B. Isoxanthohumol content in HOP was evaluated with the same method, but detection was carried at $290 \mathrm{~nm}$ (Fig. 3). NMR spectra (1H-NMR) were recorded on a DRX Avance ${ }^{\mathrm{TM}} 600(600 \mathrm{MHz})$ instrument (Bruker, Billerica, USA) in acetone-d6 (Fig. 4).

\section{Animal study}

The study was conducted on 5612 -week-old Wistar rats (28 males and 28 females, weighing $208.2 \pm 17.3 \mathrm{~g}$ ) that were housed under standard conditions of temperature $\left(21-23^{\circ} \mathrm{C}\right)$, humidity $(60-70 \%)$, and a light-dark cycle (12:12 h). Animals were fed with a standard diet (LSM, Agropol, Motycz, Poland). Access to food and water was ad libitum and was monitored once daily.

Acclimated animals were randomized into 7 groups of 8 animals each ( 4 females and 4 males) receiving either XN or HOP: XN was administered either iv. (group XN-IV: $10 \mathrm{mg} / \mathrm{kg}$ ), or p.o. (groups XN-L, XN-M and XN-H receiving 40, 100 and $200 \mathrm{mg} / \mathrm{kg}$, respectively). Extract obtained from hops was administered p.o. and its doses were based on XN content (groups HOP-L, HOP-M and HOP-H received the extract at doses equivalent to $\mathrm{XN}$ dose of 40 , 100 and $200 \mathrm{mg} / \mathrm{kg}$, respectively).

For each oral dose level, appropriate amounts of XN powder or HOP were dissolved in dimethyl sulfoxide (DMSO) (Sigma-Aldrich, Darmstadt, Germany) (1 g of XN in $1 \mathrm{~mL}$ of DMSO) and then diluted in $0.9 \%$ saline solution. Animals received a single oral dose by gavage (40, 100 or $200 \mathrm{mg} / \mathrm{kg}$ in $2 \mathrm{~mL}$ solution/ $\mathrm{kg}$ ). The animals in the XNIV group were given an iv. injection $(10 \mathrm{mg} / \mathrm{kg}$ in $2 \mathrm{~mL}$ solution $/ \mathrm{kg}$ ) of XN dissolved in DMSO (1 $\mathrm{g}$ of XN in $1 \mathrm{~mL}$ of DMSO and diluted in $0.9 \%$ saline solution). Blood samples $(0.3 \mathrm{~mL})$ were obtained via catheter from the tail vein of each rat at the following time points: $0,0.25,0.5,1,2,4$, $6,12,24,48,72$, and $96 \mathrm{~h}$. After each blood draw, $0.3 \mathrm{~mL}$ of $0.9 \%$ saline solution was injected iv. and the catheter was flushed with heparinized saline $(20 \mathrm{U} / \mathrm{mL})$. Blood samples were placed in collection tubes coated with heparin and stored on ice immediately after collection. Samples were stored at $-80^{\circ} \mathrm{C}$ until analysis for $\mathrm{XN}$.

Study protocol was approved by the First Local Ethic Committee for Animal Experiments in Wrocław, Poland, and animal experiments were therefore performed in accordance with ARRIVE guidelines and were carried out in accordance with EU Directive 2010/63/EU for animal experiments.

\section{Sample preparation}

Sample preparation procedure have been adapted from Legette et al. ${ }^{4}$ with minor modifications. Aliquots of $50 \mu \mathrm{L}$ of whole blood in duplicate were diluted with sodium acetate buffer (0.1M, pH 4.7), spiked with naringenin (NAR) (12.6 ng in 2-propanol) (Sigma-Aldrich,) as the internal standard, and treated with $600 \mathrm{U}$ of Helix pomatia hydrolases dissolved in sodium acetate buffer (Sigma-Aldrich) for $3 \mathrm{~h}$ at $37^{\circ} \mathrm{C}$ in a total volume of $600 \mu \mathrm{L}$ to convert conjugates (glucuronides and sulfates) into their free aglycone forms. After incubation, solutions were extracted thrice with diethyl ether $(1 \mathrm{~mL})$ and centrifuged for $1 \mathrm{~min}$ at $8500 \mathrm{~g}$. The combined ether extracts were dried under a stream of nitrogen. The residues were dissolved in $0.1 \mathrm{~mL}$ of $0.1 \%$ formic acid solution in methanol, briefly vortexed, sonicated and analyzed directly by (LC-MS/MS).

Calibration curves were prepared by spiking blank rat whole blood with known concentrations of flavonoids 

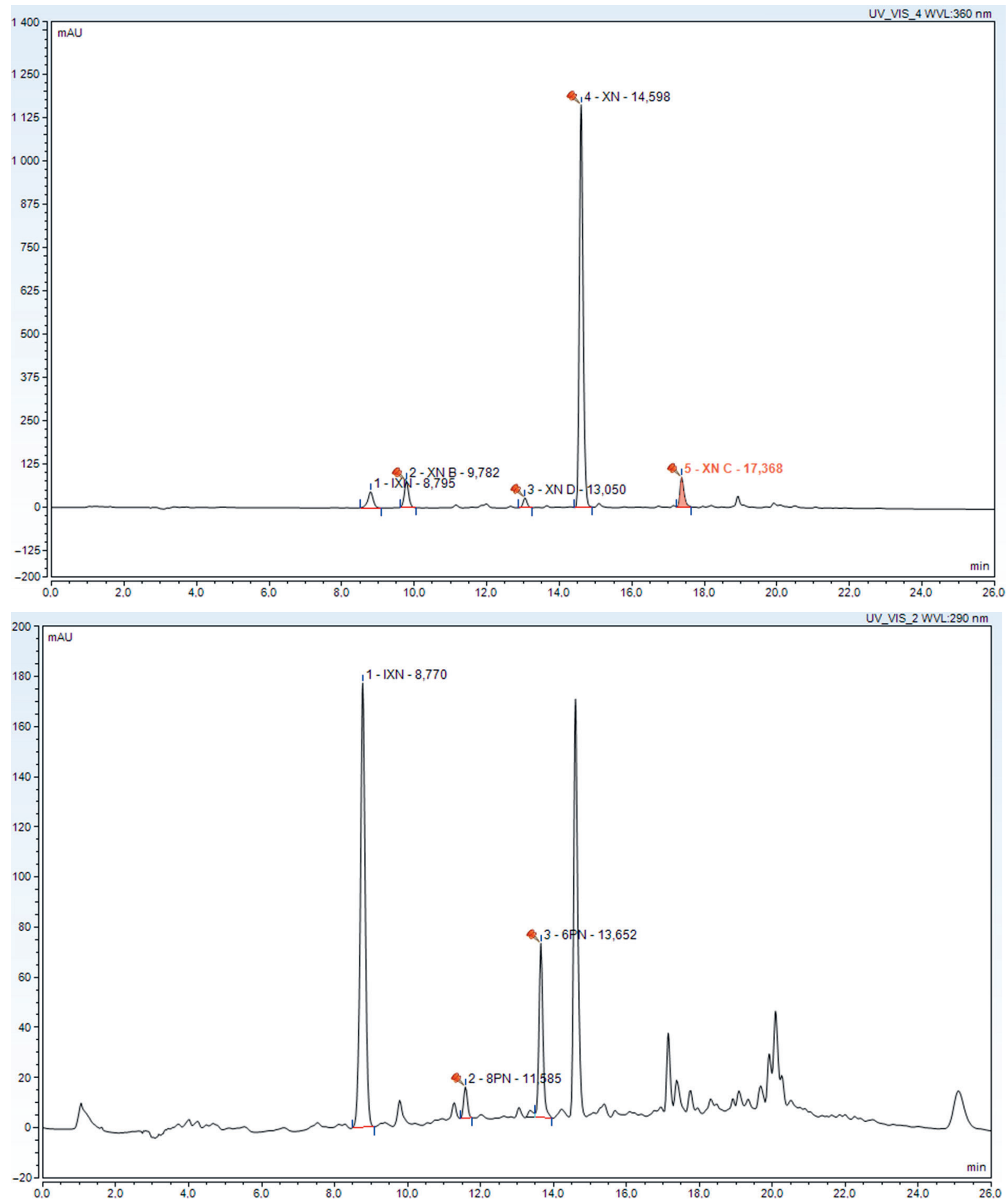

Fig. 3. HPLC chromatograms of HOP at $360 \mathrm{~nm}$ (left) and $290 \mathrm{~nm}$ (right)

and the internal standard, (NAR), using 16 concentration levels covering the entire concentration range for all analytes in the samples. The whole blood calibration samples were treated the same as the samples obtained from dosed animals. Limit of quantitation (LOQ) represents the lowest concentration in a sample that can be determined with acceptable precision and accuracy $(\mathrm{S} / \mathrm{N}>10)$, whereas limit of detection (LOD) represents the lowest concentration in a sample that can be detected ( $\mathrm{S} / \mathrm{N}>3$ ). 


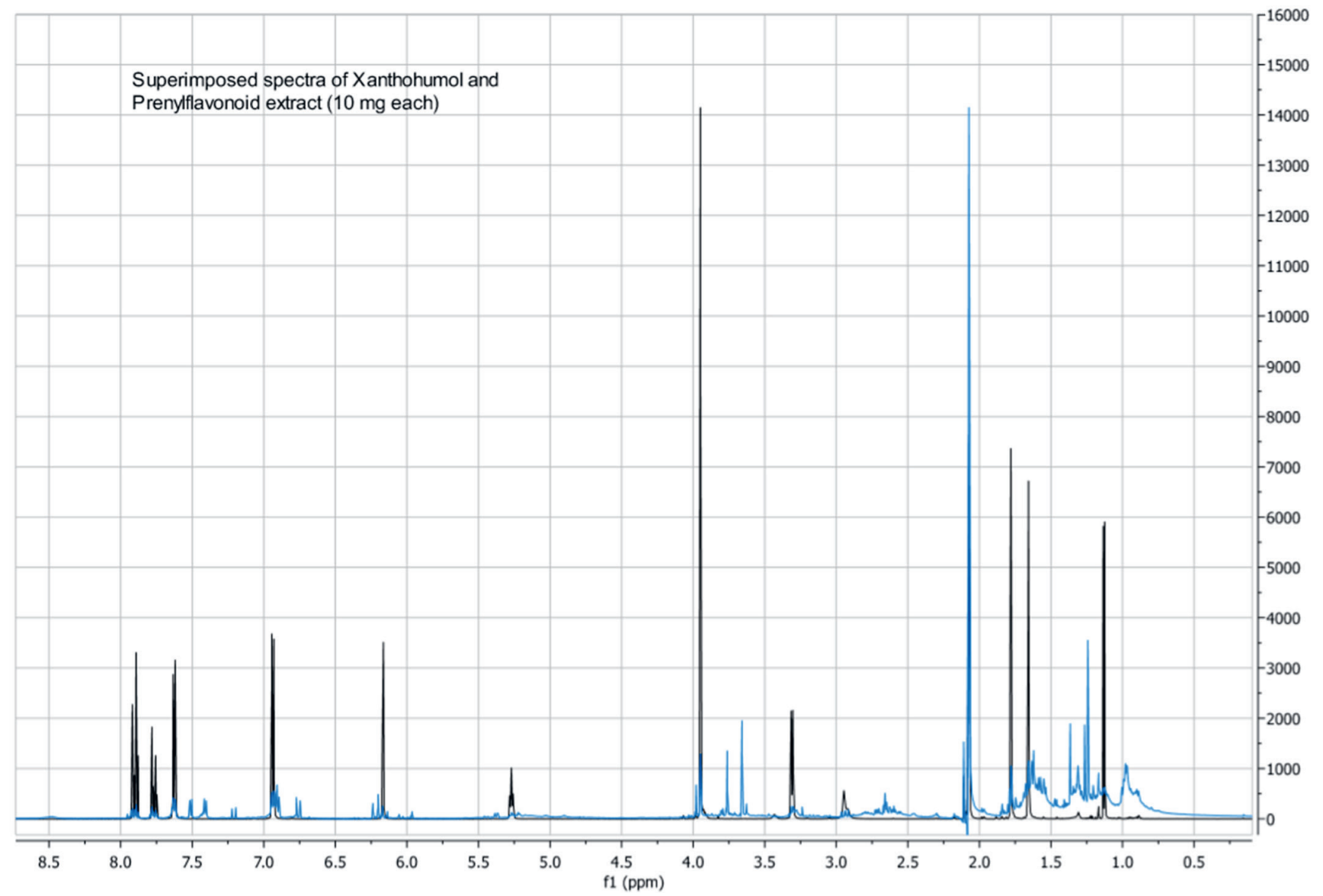

Fig. 4. ${ }^{1} \mathrm{H}$ NMR spectrum of pure XN (grey) and HOP (blue)

\section{LC-MS/MS analysis}

Liquid chromatography-mass spectrometry (LC-MS/MS) was performed on an Agilent 6400 triple quadrupole instrument (Agilent) operated at a source temperature of $350^{\circ} \mathrm{C}$ with a needle voltage of $4500 \mathrm{kV}$. Nitrogen was used as the source gas, curtain gas, and collision gas. Selected reaction monitoring (SRM) experiments were conducted at collision energies ranging from 25 to $40 \mathrm{eV}$. Concentrations were calculated using the internal standard calibration method.

The Agilent 1200 HPLC system (Agilent) was used in this study. Chromatographic separations of prenylflavonoids were achieved on a $2.6 \mu \mathrm{m}$ Accucore C8 column $150 \times 3 \mathrm{~mm}$ (Thermo Fisher Scientific) eluted in a gradient from $25 \%$ to $60 \%$ solvent B ( $0.1 \%$ formic acid in $\mathrm{ACN}$ ) in solvent $\mathrm{A}$ (aqueous $0.1 \%$ formic acid) over $8.5 \mathrm{~min}$ at a flow rate of $0.5 \mathrm{~mL} / \mathrm{min}$ after an initial $2.0 \mathrm{~min}$ at $25 \%$ solvent $\mathrm{B}$, then from $60 \% \mathrm{~B}$ to $100 \% \mathrm{~B}$ over $1.0 \mathrm{~min}$. The column was washed with $100 \%$ solvent B for $2.0 \mathrm{~min}$ and re-equilibrated at $25 \%$ solvent $\mathrm{B}$ for $7 \mathrm{~min}$ prior to each injection. Precursor-product ion transitions for SRM were developed using standards. Selected reaction monitoring transitions used for quantitation included: $[\mathrm{M}]^{-}$353-119 for $\mathrm{XN}$ and $[\mathrm{M}]^{-}$271-119 for NAR.

\section{Pharmacokinetic analysis}

Non-compartmental analysis was used to assess the pharmacokinetics (PK) of XN in rats (TP4.1 software; ThothPro, Gdańsk, Poland).

The following parameters were determined for iv. administration: the area under the concentration-time curve from time 0 to the last sampling $\left(\mathrm{AUC}_{0 \rightarrow \mathrm{t}}\right)$, the area under first moment curve from time 0 to the last sampling $\left(\mathrm{AUMC}_{0 \rightarrow t}\right)$, mean residence time $\left(\mathrm{MRT}_{0 \rightarrow t}\right)$, initial concentration $\left(\mathrm{C}_{0}\right)$, relative body clearance $\left(\mathrm{Cl}_{\mathrm{B}}\right)$, relative apparent volume of distribution at steady state $\left(\mathrm{Vd}_{\mathrm{ss}}\right)$, elimination half-life $\left(\mathrm{T}_{1 / 2 \mathrm{el}}\right)$ and biological half-life $\left(\mathrm{T}_{1 / 2}\right)$. The areas were calculated by the trapezoidal rule. For the determination of $T_{1 / 2 \mathrm{e}}$, at least 3 last datapoints from the linear portion of the terminal slope were used. The $T_{1 / 2}$ was calculated as follows:

$$
\mathrm{T}_{1 / 2}=\mathrm{MRT}_{0 \rightarrow \mathrm{t}} \times 0.693 .{ }^{9}
$$

For the oral study, $\mathrm{AUC}_{0 \rightarrow \mathrm{t}}, \mathrm{AUMC}_{0 \rightarrow \mathrm{t}}, \mathrm{MRT}_{0 \rightarrow \mathrm{t}}, \mathrm{T}_{1 / 2 \mathrm{el}}$, $\mathrm{T}_{1 / 2}$, as well as the peak concentration $\left(\mathrm{C}_{\max }\right)$ and the time when it was observed $\left(T_{\max }\right)$ were assessed. Mean absorption time (MAT) after oral administration was calculated as follows: MAT $=$ mean $M T_{0 \rightarrow t}$ p.o. - mean $M T_{0 \rightarrow t}$ iv. The bioavailability (F) of orally administered $\mathrm{XN}$ was 
calculated by comparing the AUCs of XN after p.o. and iv. administration according to the following formula:

$$
F(\%)=\frac{\text { mean } \mathrm{AUC}_{0 \rightarrow \mathrm{t}} \text { p.o. } \times \text { dose i.v. }}{\text { mean } \mathrm{AUC}_{0 \rightarrow \mathrm{t}} \text { i.v. } \times \text { dose p.o. }} \times 100 \%
$$

Since numerous samples were found to contain very low and variable concentrations of $\mathrm{XN}$, data below the limit of quantification (BLOQ) was not ignored but included calculations based on the method by Hornung and Reed..$^{10}$ All values appearing in the early part of the concentrationtime curve were substituted by the value of LOQ/2 and treated as a real value. In the elimination phase, the first BLOQ value was substituted with $\mathrm{LOQ} / 2$ and the following BLOQ values were ignored..$^{10,11}$

\section{Statistical analysis}

The distribution of PK parameters was assessed by the Shapiro-Wilk test. Almost all parameters were characterized by normal distribution and were therefore compared with Student's t-test between groups. Only $\mathrm{T}_{\max }$ lacked normal distribution and was compared using the Mann-Whitney U test. Statistical analysis was carried out by means of STATISTICA v. 13 (Tibco Software Inc., Palo Alto, USA) and Excel (Microsoft Corp., Redmond, USA).

\section{Results}

Good linear relationship was obtained in the concentration range of $4.5-4500 \mu \mathrm{g} / \mathrm{L}\left(\mathrm{y}=0.0005 \mathrm{x}+0.0003, \mathrm{R}^{2}=0.9997\right)$ of XN in whole blood. The LOQ and LOD for XN in the whole blood were $2.5 \mu \mathrm{g} / \mathrm{L}$ and $0.4 \mu \mathrm{g} / \mathrm{L}$, respectively.

Figure 3A depicts the mean serum concentration-time profile of XN. The pharmacokinetic parameters are listed in Table 1. The elimination half-life of XN was $173.9 \mathrm{~h}$ and the half-life was $7.7 \mathrm{~h}$.

The serum profile of $\mathrm{XN}$ after oral administration is shown in Fig. 3B for pure XN and in Fig. $3 \mathrm{C}$ for $\mathrm{XN}$ given in HOP. Pharmacokinetic parameters are listed in Table 1, showing the bioavailability of pure XN ranging from $0.96 \%$ to $1.16 \%$ and lower. After oral administration of pure $\mathrm{XN}$ $(40,100$ and $200 \mathrm{mg} / \mathrm{kg}$ ) and HOP in a dose equivalent for $\mathrm{XN} 200 \mathrm{mg} / \mathrm{kg}$, XN was detectable up to $96 \mathrm{~h}$, whereas after oral administration of HOP in doses equivalent for $\mathrm{XN} 40$ and $100 \mathrm{mg} / \mathrm{kg}$ no XN was detected after $72 \mathrm{~h}$. The $\mathrm{AUC}_{0 \rightarrow \mathrm{t}}$ of XN was 7.7 times and 5.0 times higher for pure XN than for HOP for doses of 100 and $200 \mathrm{mg} / \mathrm{kg}$, respectively. The $\mathrm{C}_{\mathrm{MAX}}$ of XN was 2.3 times, 8.4 times and 11.7 times higher for pure XN than for HOP for doses of 40, 100 and $200 \mathrm{mg} / \mathrm{kg}$, respectively.

Table 2 summarizes the influence of sex on XN pharmacokinetics. $\mathrm{C}_{\mathrm{MAX}}$ was higher 1.7 times and 1.8 times in females than in males receiving XN in doses of 100 and $200 \mathrm{mg} / \mathrm{kg}$, respectively.

\section{Discussion}

The concentration-time curve and the PK parameters for the intravenous administration are shown in Fig. 3A and Tables 1 and 2, respectively. As can be appreciated from Fig. 3A, a relatively long distribution phase (lasting about

Table 1. Pharmacokinetic parameters (mean $\pm S D$ ) of xanthohumol after single intravenous or oral administration to rats ( $\mathrm{n}=8 / \mathrm{group}$ ). $\mathrm{Groups} \mathrm{IV}, \mathrm{XN}-\mathrm{L}$, $\mathrm{XN}-\mathrm{M}$, and $\mathrm{XN}-\mathrm{H}$ received pure xanthohumol, whereas groups HOP-L, HOP-M and HOP-L were administered with prenylflavonoid extract that contained equivalent dose of xanthohumol

\begin{tabular}{|c|c|c|c|c|c|c|c|c|}
\hline \multirow{3}{*}{ Parameter } & \multirow{3}{*}{ Units } & \multirow{3}{*}{$\underset{10 \mathrm{mg} / \mathrm{kg}}{\mathrm{IV}}$} & \multicolumn{6}{|c|}{ Oral } \\
\hline & & & \multicolumn{2}{|c|}{$40 \mathrm{mg} / \mathrm{kg}$} & \multicolumn{2}{|c|}{$100 \mathrm{mg} / \mathrm{kg}$} & \multicolumn{2}{|c|}{$200 \mathrm{mg} / \mathrm{kg}$} \\
\hline & & & $X N-L$ & HOP - L & $X N-M$ & HOP - M & $\mathrm{XN}-\mathrm{H}$ & $\mathrm{HOP}-\mathrm{H}$ \\
\hline $\mathrm{AUC}_{0 \rightarrow \mathrm{t}}$ & $m g^{*} h / L$ & $13.60 \pm 5.72$ & $0.63 \pm 0.34$ & - & $1.31 \pm 0.12$ & $0.17 \pm 0.06^{*}$ & $1.44 \pm 0.49$ & $0.29 \pm 0.16^{*}$ \\
\hline$A \cup M C_{0 \rightarrow t}$ & $m g^{*} h^{*} h / L$ & $93.95 \pm 40.01$ & $24.04 \pm 14.94$ & - & $42.83 \pm 6.06$ & $4.18 \pm 2.56^{*}$ & $44.91 \pm 12.04$ & $8.56 \pm 6.41^{*}$ \\
\hline$M R T_{0 \rightarrow t}$ & $h$ & $7.95 \pm 4.99$ & $30.20 \pm 16.23$ & - & $33.01 \pm 5.85$ & $21.34 \pm 10.02^{*}$ & $32.36 \pm 6.35$ & $24.98 \pm 10.38$ \\
\hline MAT & h & - & 22.25 & - & 25.06 & 13.39 & 24.41 & 17.03 \\
\hline $\mathrm{Cl}_{\mathrm{B}(\mathrm{rel})}$ & $\mathrm{L} / \mathrm{h} / \mathrm{kg}$ & $0.87 \pm 0.33$ & - & - & - & - & - & - \\
\hline$V d_{s s(r e l)}$ & $\mathrm{L} / \mathrm{kg}$ & $7.67 \pm 6.78$ & - & - & - & - & - & - \\
\hline $\mathrm{T}_{1 / 2 \mathrm{el}}$ & $\mathrm{h}$ & $173.89 \pm 131.09$ & $127.49 \pm 136.54$ & - & $144.1 \pm 131.5$ & - & - & - \\
\hline $\mathrm{T}_{1 / 2}$ & h & $7.67 \pm 7.78$ & $20.93 \pm 11.25$ & - & $22.88 \pm 4.05$ & $14.08 \pm 7.54^{*}$ & $22.42 \pm 4.40$ & $17.31 \pm 7.20$ \\
\hline$C_{\text {MAX }}$ & $\mu g / L$ & $9061 \pm 4543$ & $22.02 \pm 2.18$ & $9.46 \pm 9.37^{*}$ & $90.64 \pm 28.15$ & $10.73 \pm 4.47^{*}$ & $168.16 \pm 59.38$ & $14.38 \pm 7.95^{*}$ \\
\hline $\mathrm{T}_{\text {MAX }}$ & $\mathrm{h}$ & - & $1.31 \pm 0.56$ & $16.91 \pm 21.99$ & $1.19 \pm 1.82$ & $1.45 \pm 1.42$ & $0.88 \pm 0.48$ & $7.06 \pm 9.84$ \\
\hline F & $\%$ & - & 1.16 & - & 0.96 & 0.13 & 0.53 & 0.11 \\
\hline
\end{tabular}

IV - intravenous; $A \cup C_{0 \rightarrow t}$ - area under the curve; $A_{U M C_{0 \rightarrow t}}$ - area under the first moment curve; $M R T_{0 \rightarrow t}$ - mean residence time; $M A T$ - mean absorption time; $\mathrm{Cl}_{\mathrm{B}(\text { (rel) }}$ - relative body clearance; $\mathrm{Vd}_{\mathrm{ss}(\mathrm{rel})}$ - relative volume of distribution at steady state; $\mathrm{T}_{1 / 2 \mathrm{l}}$ - elimination half-life; $\mathrm{T}_{1 / 2}-$ half-life; $\mathrm{C}_{\mathrm{MAX}}$ - peak plasma concentration; $\mathrm{T}_{\text {MAX }}$ - time to reach peak plasma concentration; $\mathrm{F}$ - absolute oral bioavalability.

* $\mathrm{p}<0.05$ as compared to the equivalent dose of pure xanthohumol. 
Table 2. The influence of sex on pharmacokinetic parameters (mean \pm SD) of xanthohumol after single intravenous or oral administration of pure xanthohumol to rats of both sexes ( $n=4 /$ group)

\begin{tabular}{|c|c|c|c|c|c|c|c|c|c|}
\hline \multirow{3}{*}{ Parameter } & \multirow{3}{*}{ Units } & \multirow{2}{*}{\multicolumn{2}{|c|}{$\frac{\mathrm{IV}}{10 \mathrm{mg} / \mathrm{kg}}$}} & \multicolumn{6}{|c|}{ Oral } \\
\hline & & & & \multicolumn{2}{|c|}{$40 \mathrm{mg} / \mathrm{kg}$} & \multicolumn{2}{|c|}{$100 \mathrm{mg} / \mathrm{kg}$} & \multicolumn{2}{|c|}{$200 \mathrm{mg} / \mathrm{kg}$} \\
\hline & & males & females & males & females & males & females & males & females \\
\hline$A \cup C_{0 \rightarrow t}$ & $m g^{*} h / L$ & $10.41 \pm 2.96$ & $16.79 \pm 6.04$ & $0.42 \pm 0.37$ & $0.84 \pm 0.07$ & $1.26 \pm 0.12$ & $1.36 \pm 0.09$ & $1.15 \pm 0.25$ & $1.73 \pm 0.50$ \\
\hline$A \cup M C_{0 \rightarrow t}$ & $m g^{*} h^{*} h / L$ & $78.64 \pm 40.06$ & $109.26 \pm 33.59$ & $15.76 \pm 17.01$ & $32.32 \pm 4.50$ & $46315 \pm 3550$ & $39.35 \pm 6.06$ & $42577 \pm 11212$ & $47.24 \pm 12.38$ \\
\hline $\mathrm{MRT}_{0 \rightarrow \mathrm{t}}$ & h & $7.21 \pm 1.85$ & $8.70 \pm 6.72$ & $22.10 \pm 19.55$ & $38.30 \pm 3.67$ & $37.11 \pm 4.54$ & $28.91 \pm 3.76$ & $37.07 \pm 5.04$ & $27.65 \pm 3.29^{*}$ \\
\hline MAT & h & - & - & 14.89 & 29.60 & 29.90 & 20.21 & 29.85 & 18.95 \\
\hline $\mathrm{Cl}_{\mathrm{B}(\text { rel) }}$ & $\mathrm{L} / \mathrm{h} / \mathrm{kg}$ & $1.03 \pm 0.26$ & $0.70 \pm 0.31$ & - & - & - & - & - & - \\
\hline$V d_{s s(r e l)}$ & $\mathrm{L} / \mathrm{kg}$ & $7.15 \pm 1.72$ & $8.18 \pm 9.41$ & - & - & - & - & - & - \\
\hline$T_{1 / 2 \mathrm{el}}$ & h & $274.00 \pm 114.91$ & $73.76 \pm 33.32$ & $179.78 \pm 176.49$ & $75.21 \pm 25.35$ & $122.8 \pm 87.12$ & $172.5 \pm 169.8$ & - & - \\
\hline $\mathrm{T}_{1 / 2}$ & h & $4.99 \pm 1.28$ & $6.03 \pm 4.66$ & $15.31 \pm 13.55$ & $26.54 \pm 2.54$ & $25.72 \pm 3.14$ & $20.03 \pm 2.61$ & $25.69 \pm 3.49$ & $19.16 \pm 2.28$ \\
\hline$C_{\text {MAX }}$ & $\mu \mathrm{g} / \mathrm{L}$ & $11329 \pm 4733$ & $6793 \pm 2930$ & $21.50 \pm 2.82$ & $22.55 \pm 1.01$ & $66.61 \pm 12.44$ & $114.67 \pm 16.58^{*}$ & $119.58 \pm 18.96$ & $216.74 \pm 44.41^{*}$ \\
\hline $\mathrm{T}_{\operatorname{MAX}}$ & $\mathrm{h}$ & - & - & $0.88 \pm 0.22$ & $1.75 \pm 0.43$ & $1.88 \pm 2.38$ & $0.50 \pm 0.00$ & $0.75 \pm 0.25$ & $1.00 \pm 0.61$ \\
\hline $\mathrm{F}$ & $\%$ & - & - & 1.01 & 1.25 & 1.21 & 0.81 & 0.55 & 0.52 \\
\hline
\end{tabular}

IV - intravenous; $\mathrm{AUC}_{0 \rightarrow \mathrm{t}}$ - area under the curve; $\mathrm{AUMC}_{0 \rightarrow \mathrm{t}}$ - area under the first moment curve; $\mathrm{MRT}_{0 \rightarrow \mathrm{t}}$ - mean residence time; $\mathrm{MAT}$ - mean absorption time; $\mathrm{Cl}_{\mathrm{B}(\mathrm{rel})}$ - relative body clearance; $V \mathrm{~d}_{\text {ss(rel) }}$ - relative volume of distribution at steady state; $T_{1 / 2 \mathrm{el}}$ - elimination half-life; $T_{1 / 2}-$ half-life; $\mathrm{C}_{\mathrm{MAX}}-$ peak plasma concentration; $T_{\text {MAX }}$ - time to reach peak plasma concentration; $F$ - absolute oral bioavalability.

* $\mathrm{p}<0.05$ as compared to males receiving the same dose of xanthohumol.

$10 \mathrm{~h}$ ) is followed by an even longer and flat elimination. In some individuals (particularly males), concentrations in the elimination phase even exceed the concentrations at the end of the distribution phase. A similar rise in $\mathrm{XN}$ concentration after iv. administration of $\mathrm{XN}$ to rats has been reported by Legette et al., ${ }^{4}$ who have suggested enterohepatic recirculation as the underlying mechanism. Enterohepatic recirculation of hop prenylated phenols suggest also observation reported by Rad et al. ${ }^{12}$ As can be seen in Table 2, no statistically significant differences between sexes have been found for iv. administration. Although there was a tendency of higher internal exposure (as expressed by $\mathrm{AUC}_{0 \rightarrow \mathrm{t}}$ ) in females, high interindividual variability in this group and small number of animals preclude any firm conclusions. A relatively long MRT does not differ much between males and females. Volume of distribution is high and may suggest deep penetration into tissue(s). Although $\mathrm{Cl}_{\mathrm{B}}$ is slightly higher in males, the $\mathrm{T}_{1 / 2 \mathrm{el}}$ estimates are also higher in this group suggesting somewhat slower elimination in males. The latter parameter, however, should be interpreted with caution as it may be biased by the aforementioned enterohepatic recirculation. The $T_{1 / 2}$, which is less affected by the lack of linearity in the elimination phase, does not confirm any sex-related difference in XN elimination. The initial concentrations were somewhat higher in males but, again, high interindividual variability precludes firm conclusions.

Studies using the Caco-2 human intestinal epithelial model indicate that hop prenyled flavonoids are absorbed at a slow to moderate rate through the intestinal epithelium. XN accumulates in intestinal epithelial cells and then are gradually released to the general circulation, ${ }^{13}$ while $8 \mathrm{PN}$ crosses the intestinal epithelium via passive diffusion. ${ }^{14}$ Tables 1 and 2 summarize the PK of XN administered orally at the dose of $40 \mathrm{mg} / \mathrm{kg}$. Due to very low XN concentrations observed after administration of the HOP-L formulation, only the $\mathrm{C}_{\mathrm{MAX}}$ and the corresponding $\mathrm{T}_{\text {MAX }}$ could be assessed. In the case of XN-L formulation, the $\mathrm{C}_{\mathrm{MAX}}$ was significantly higher as compared to HOP-L, and all PK phases could have been observed (Fig. 3B,C). Steep increase in blood XN followed by a pointed peak of $\mathrm{C}_{\mathrm{MAX}}$ may suggest zero-order absorption. Similar to the iv. administration, the distribution phase is followed by a flat and long elimination phase. No sex-dependent differences were observed in the PK parameters. A low AUC translated into low bioavailability of about $1 \%$. Longer MRT values, as compared to iv. administration, resulted in very long MAT, particularly in females. Such a long MAT value could suggest a flip-flop phenomenon where the prolonged absorption is a limiting factor for the elimination. ${ }^{15}$ However, this is not the case in the present study, as the absorption seems to be fast and there is no difference in the slope of the elimination phase between the intravenous and the oral studies (as seen in the $\mathrm{T}_{1 / 2 \mathrm{el}}$ ). Therefore, the current MAT estimations seem to be biased by the very low bioavailability of the oral formulations on the one hand, and slow elimination of the absorbed fraction of the drug on the other.

The administration of $\mathrm{XN}$ at the dose of $100 \mathrm{mg} / \mathrm{kg}$ in the formulation $\mathrm{XN}-\mathrm{M}$ resulted in the proportional increase in the AUC without any visible effect on the absorption phase as seen in the lack of change in the MRT and MAT (Tables 1 and 2). This questions the possibility of zero-order absorption suggested by the shape of the curve in both $\mathrm{XN}-\mathrm{L}$ and $\mathrm{XN}-\mathrm{M}$ groups. The $\mathrm{C}_{\max }$ 

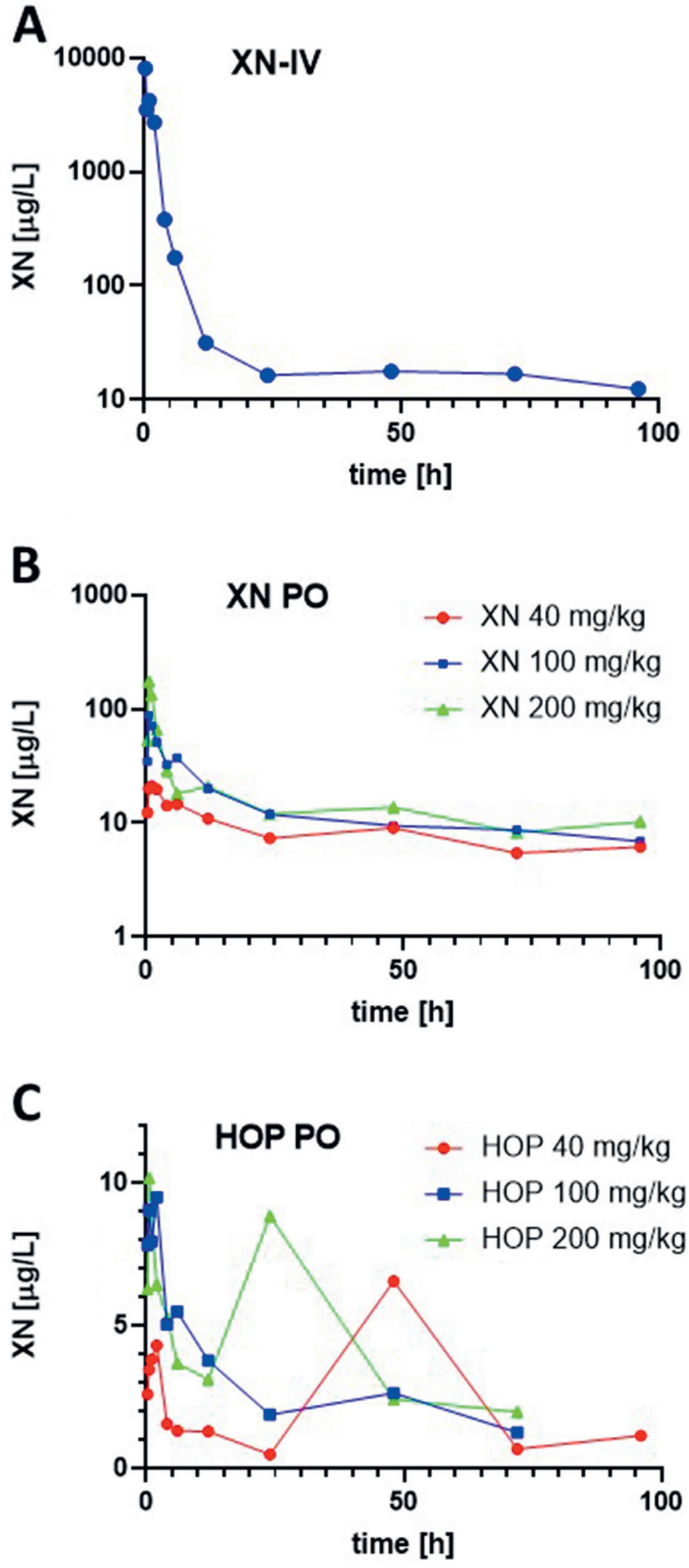

Fig. 5. Concentration-time profiles of xanthohumol in rat plasma following (A) intravenous injection (XN IV) of $10 \mathrm{mg} / \mathrm{kg}$, (B) oral administration of pure xanthohumol (XN PO): $40 \mathrm{mg} / \mathrm{kg}, 100 \mathrm{mg} / \mathrm{kg}$ and $200 \mathrm{mg} / \mathrm{kg}$, and (C) oral administration of prenylflavonoid extract (HOP PO): $40 \mathrm{mg} \mathrm{XN/kg,} 100 \mathrm{mg} \mathrm{XN/kg}$ and $200 \mathrm{mg} X N / \mathrm{kg}$. Data is expressed as mean from 8 rats

was much higher in XN-M group, particularly in females, but the $\mathrm{T}_{\max }$ was similarly short. Both half-lives were similar to the XN-L group, indicating no significant change in the elimination of the compound. In rats treated with the HOP-M formulation, the AUC was more than 7 times lower as compared to the rats administered with XN-M
(Table 1). Moreover, very low values (below LOQ) in 3 out of 4 females precluded PK analysis in these individuals. The MRT was significantly shorter and the mean $C_{\text {MAX }}$ was about 9 times lower. The mean bioavailability of $0.13 \%$ should be considered extremely low. In the HOP-M group, it was not possible to calculate $\mathrm{T}_{1 / 2 \mathrm{el}}$ due to the lack of linearity in the elimination phase.

The saturation of XN absorption was much more visible in the PK of XN after the administration of the highest dose - $200 \mathrm{mg} / \mathrm{kg}$ (Tables 1 and 2). In the XN-H group, the mean AUC increased only very slightly as compared to the lower dose (XN-M), which translated into a drop in bioavailability $(0.53 \%)$. Although the MRT, MAT and $\mathrm{T}_{1 / 2}$ were not changed, the lack of linearity in the elimination phase ( $\mathrm{T}_{1 / 2 \mathrm{el}}$ impossible to calculate in 5 out of 8 individuals) may suggest limited/prolonged absorption. $C_{\max }$, however, was proportionally higher as compared to the $\mathrm{XN}-\mathrm{M}$ group. In the case of the HOP-L group, the saturated absorption is also seen in the less than proportional increase in the AUC and the drop in the bioavailability (as compared to HOP-M). The mean $\mathrm{C}_{\text {MAX }}$ is only slightly higher, and MAT, $\mathrm{T}_{\text {MAX }}$ as well as $\mathrm{T}_{1 / 2}$, are prolonged. The concentration-time curve for this group lacks linear elimination and the presence of a secondary peak at $24 \mathrm{~h}$ further supports the presence of prolonged/disturbed absorption.

The lower bioavailability of HOP at every dosage level in comparison to similar dosage of pure $\mathrm{XN}$ is definitively associated with the complex composition of the prenylflavonoid extract. Despite the undertaken procedure of HOP preparation being highly selective for polyphenol fraction, the complete composition of the HOP cannot be determined. On the basis of the combined data from the HOP ${ }^{1} \mathrm{H}$ NMR spectra (Fig. 4, especially the aromatic part 8.0-6.0 ppm) and HPLC analysis (Fig. 3), a rough estimation of total prenylflavonoid content in HOP would be about 30-35\%, with XN and IXN being the most abundant. Therefore, it cannot be even speculated whether the complex matrix or other prenylflavonoids affects the bioavailability of XN from HOP.

\section{Conclusions}

It is concluded that the XN PK in rats after intravenous administration is characterized by extensive distribution followed by delayed elimination from the body. Enterohepatic recirculation is likely to play a role in XN PK. Some fraction of the orally administered XN reaches the central compartment rapidly; however, the overall absorption is very limited and probably saturable. The formulationdependent factors also play an important role in the bioavailability of the drug. Although the $\mathrm{C}_{\mathrm{MAx}}$ concentration was higher in females receiving $\mathrm{XN}$ orally compared to males, the other pharmacokinetic parameters were unaffected by rats' sex. Therefore, the same doses of XN may be administered to males and females. 


\section{ORCID iDs}

Beata Nowak (D) https://orcid.org/0000-0003-0014-6344 Błażej Poźniak (D) https://orcid.org/0000-0002-5813-1404 Jarosław Popłoński (D) https://orcid.org/0000-0002-7254-5937 Łukasz Bobak (D) https://orcid.org/0000-0002-4332-7252 Agnieszka Matuszewska (D) https://orcid.org/0000-0003-1082-0793 Joanna Kwiatkowska (D) https://orcid.org/0000-0002-2871-3366 Wojciech Dziewiszek (D) https://orcid.org/0000-0002-5788-5642

Ewa Huszcza (1) https://orcid.org/0000-0002-5950-3695 Adam Szeląg (D) https://orcid.org/0000-0001-8104-5267

\section{References}

1. Zanoli P, Zavatti M. Pharmacognostic and pharmacological profile of Humulus Iupulus L. J Ethnopharmacol. 2008;116:383-396. doi:10. 1016/j.jep.2008.01.011

2. Erkkola R, Vervarcke S, Vansteelandt S, Rompotti P, De Keukeleire D, Heyerick A. A randomized, double-blind, placebo-controlled, crossover pilot study on the use of a standardized hop extract to alleviate menopausal discomforts. Phytomedicine. 2010;17:389-396. doi:10. 1016/j.phymed.2010.01.007

3. Milligan SR, Kalita JC, Pocock V, et al. The endocrine activities of 8-prenylnaringenin and related hop (Humulus lupulus L.) flavonoids. J Clin Endocrinol Metab. 2000;85:4912-4915. doi:10.1210/jcem.85.12.7168

4. Legette $L, M a L$, Reed $R L$, et al. Pharmacokinetics of xanthohumol and metabolites in rats after oral and intravenous administration. Mol Nutr Food Res. 2012;56:466-474. doi:10.1002/mnfr.201100554

5. Hussong R, Frank N, Knauft J, et al. A safety study of oral xanthohumol administration and its influence on fertility in Sprague Dawley rats. Mol Nutr Food Res. 2005;49:861-867. doi:10.1002/mnfr.200500089

6. Popłoński J, Turlej E, Sordon S, et al. Synthesis and antiproliferative activity of minor hops prenylflavonoids and new insights on prenyl group cyclization. Molecules. 2018;23. doi:10.3390/molecules 23040776
7. Bartmańska A, Huszcza E, Tronina T. Transformation of isoxanthohumol by fungi. J Mol Catal B Enzym. 2009;61:221-224. doi:10.1016/j. molcatb.2009.07.008

8. Anioł M, Szymańska K, Zołnierczyk A. An efficient synthesis of the phytoestrogen 8-prenylnaringenin from isoxanthohumol with magnesium iodide etherate. Tetrahedron. 2008;64:9544-9547. doi:10. 1016/j.tet.2008.07.072

9. Riviere JE. Comparative Pharmacokinetics. Oxford, UK: Wiley-Blackwell; 2011. doi:10.1002/9780470959916

10. Hornung RW, Reed LD. Estimation of average concentration in the presence of nondetectable values. ApplOccuo Env Hyg. 1990;5:46-51.

11. Ahn JE, Karlsson MO, Dunne A, Ludden TM. Likelihood based approaches to handling data below the quantification limit using NONMEM VI. J Pharmacokinet Pharmacodyn. 2008;35:401-421. doi:10. 1007/s10928-008-9094-4

12. Rad M, Hümpel M, Schaefer $\mathrm{O}$, et al. Pharmacokinetics and systemic endocrine effects of the phyto-oestrogen 8-prenylnaringenin after single oral doses to postmenopausal women. Br J Clin Pharmacol. 2006;62:288-296. doi:10.1111/j.1365-2125.2006.02656.x

13. Pang Y, Nikolic D, Zhu D, et al. Binding of the hop (Humulus lupulus L.) chalcone xanthohumol to cytosolic proteins in Caco-2 intestinal epithelial cells. Mol Nutr Food Res. 2007;51:872-879. doi:10.1002/ mnfr.200600252.

14. Nikolic D, Li Y, Chadwick LR, Van Breemen RB. In vitro studies of intestinal permeability and hepatic and intestinal metabolism of 8-prenylnaringenin, a potent phytoestrogen from hops (Humulus lupulus L.). Pharm Res. 2006;23:864-872. doi:10.1007/s11095-006-9902-8

15. Tanigawara Y, Yamaoka K, Nakagawa T, Uno T. Moment analysis for the separation of mean in vivo disintegration, dissolution, absorption, and disposition time of ampicillin products. J Pharm Sci. 1982;71: 1129-1133. doi:10.1002/jps.2600711013 